\title{
Gossamer Roadmap Technology Reference Study for a Solar Polar Mission
}

\author{
Macdonald, M. ${ }^{1}$, McGrath, C. \\ Strathclyde Space Institute, University of Strathclyde, Glasgow, Scotland \\ Appourchaux, T., \\ Université Paris Sud CNRS, Bâtiment 121, Orsay Cedex, France \\ Dachwald, B., \\ FH Aachen University of Applied Sciences, 52064 Aachen, Germany
}

Finsterle, W.

Physikalisch-Meteorologisches Observatorium Davos / World Radiation Center, Davos, Switzerland

Gizon, L.,

Max Planck Institute for Solar System Research, Katlenburg-Lindau, Germany

Liewer, P.C..,

Jet Propulsion Laboratory, California Institute of Technology, Pasadena, USA.

McInnes, C.R.,

Strathclyde Space institute, University of Strathclyde, Glasgow, Scotland

Mengali, G.,

University of Pisa, Pisa, Italy

Seboldt, W.,

German Aerospace Center (DLR), 28359 Bremen, Germany

Sekii, T.,

National Astronomical Observatory of Japan, Tokyo, Japan

Solanki, S. K.,

Max-Planck-Institute for Solar System Research, Katlenburg, Germany

Velli, M.,

University of Florence, Florence, Italy

Wimmer-Schweingruber, R.F., University of Kiel, Kiel, Germany

Peter Spietz

German Aerospace Center (DLR), 28359 Bremen, Germany

Ruedeger Reinhard

European Space Agency, 2201 AZ Noordwijk, The Netherlands

\begin{abstract}
A technology reference study for a solar polar mission is presented. The study uses novel analytical methods to quantify the mission design space including the required sail performance to achieve a given solar polar observation angle within a given timeframe and thus to derive mass allocations for the remaining spacecraft sub-systems, that is excluding the solar sail sub-system. A
\end{abstract}

\footnotetext{
${ }^{1}$ Department of Mechanical \& Aerospace Engineering, malcolm.macdonald.102@strath.ac.uk
} 
parametric, bottom-up, system mass budget analysis is then used to establish the required sail technology to deliver a range of science payloads, and to establish where such payloads can be delivered to within a given timeframe. It is found that a solar polar mission requires a solar sail of side-length 100 - $125 \mathrm{~m}$ to deliver a 'sufficient value' minimum science payload, and that a $2.5 \mu \mathrm{m}$ sail film substrate is typically required, however the design is much less sensitive to the boom specific mass.

\section{Introduction}

T

ERRESTRIAL observations of the Sun are restricted to within the ecliptic plane, and hence \pm 7.25 deg., of the solar equator, whilst space-based observations have largely been similarly restricted. The Ulysses spacecraft used a Jupiter gravity assist to pass over the solar poles, obtaining field and particle measurements but no images of the poles. Furthermore, the Ulysses orbit is highly elliptical, with a pole revisit time of approximately 6 years. It is desired that future solar analysis be performed much closer to the Sun, as well as from an out-of-ecliptic perspective. ESA's Cosmic Vision 2015 - 2025 Programme mission Solar Orbiter intends to deliver a science suite of order $180 \mathrm{~kg}$ to a maximum inclination of order 35 degrees with respect to the solar equator and to a minimum solar approach radius of 0.22 au [1].

The inability of the Solar Orbiter mission to attain a solar polar orbit highlights the difficulty of such a goal with conventional chemical or electric propulsion. Solar sailing has previously been identified as a key enabling technology to place a spacecraft into an high-inclination, or polar orbit over the Sun [2]; such a mission concept has been extensively studied since the nineteen seventies [3-6]. This paper presents an analysis of the mission design trade-space to inform future technology development within the DLR-ESA Gossamer Technology Roadmap [7, 8], whilst seeking to inform analysis of the 'sufficient value' minimum science payload [9].

\section{Mission Architecture \& Analysis}

In many previous solar polar mission concepts $[3-6,10-13]$ the mission science goals required an Earth resonant orbit, placing the spacecraft near to the solar limb as seen from Earth to allow observation of the corona along the Sun-Earth line. An Earth resonant orbit limits the orbit radius to $N^{-2 / 3}$ au, where $N$ is an integer representing the resonant value. If this science requirement is not present then the only other reason to adopt a resonant orbit would be to allow continuous spacecraft visibility from Earth for ease of spacecraft operations. It is of note that in mission concepts that do not require a resonant orbit, a resonant orbit radius is still typically chosen $[9,14]$. 
The peak-duration of communication blackouts due to solar conjunctions against a range of orbit radius for both X-band and K-band communications is shown in Fig. 1 assuming perpendicular relative motion. Note that a 4-degree field-of-view exclusion is assumed for X-band communications, while a 1.5-degree field-of-view exclusion is assumed for K-band communications. It is seen from Fig. 1 that the likely peak-duration of communication blackouts, on a solar polar orbit, due to solar conjunctions is around two-days for X-band systems and less than one-day for K-band systems. It is concluded that a resonant orbit is not required for spacecraft operations.

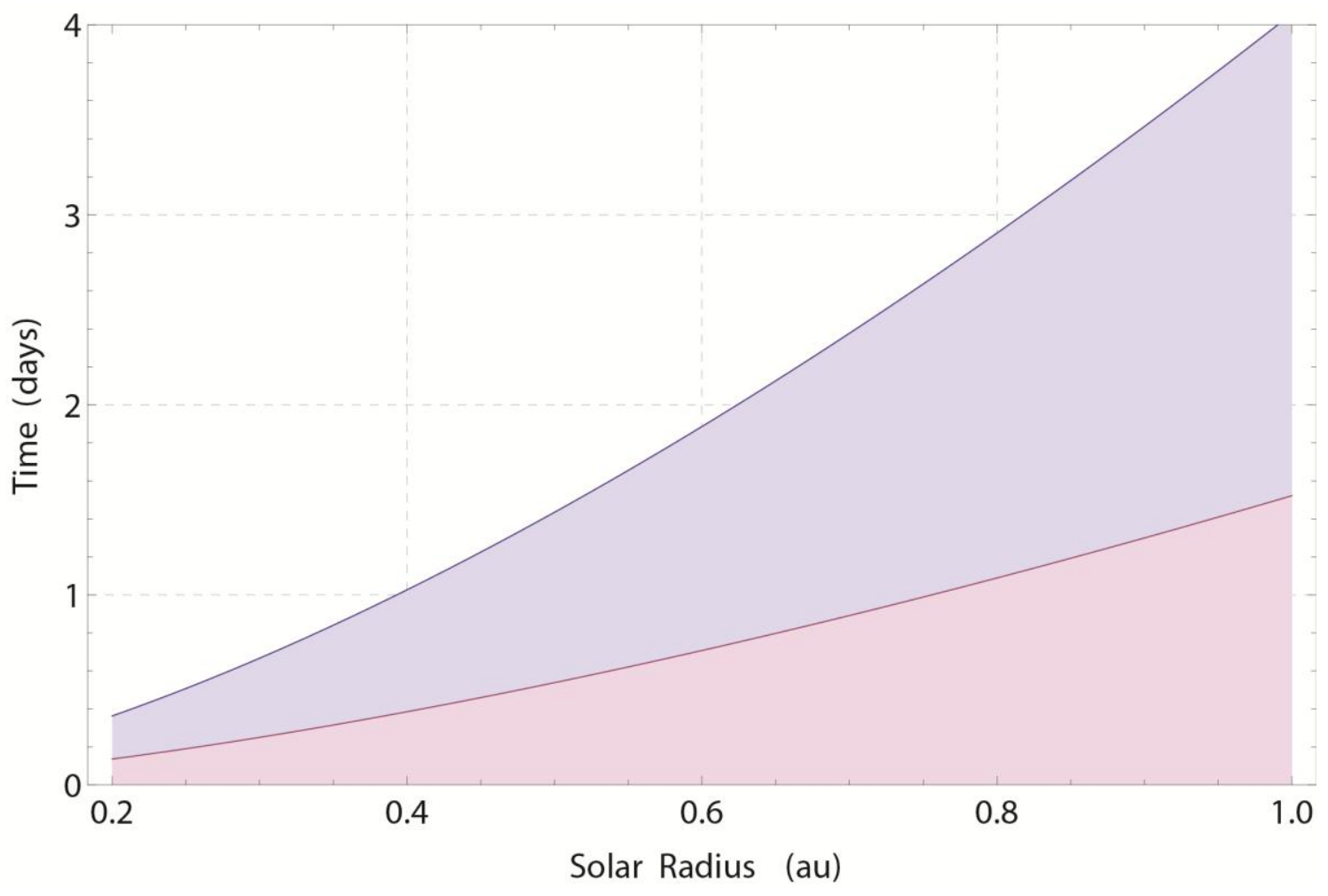

Fig. 1 Peak-duration of communication blackout due to solar conjunction against orbit radius for X-band (top) and K-band (bottom) communication, assuming perpendicular motion.

\section{A. Solar Pole Visibility}

The visibility of the solar pole is illustrated in Fig. 2 for a given observer location, determined by the observers distance (orbit radius, assumed equal to the orbit semi-major axis) and the observers elevation above the pole (the orbit inclination measured from the Solar equator, equal to the inclination from the Ecliptic plane plus 7.25 degrees).

Using the cosine rule the observers Slant Range, $S R$, to the solar pole can be determined as,

$$
S R^{2}=R_{S}^{2}+r^{2}-2 R_{S} r \sin i_{s e}
$$

where $i_{s e}>i_{s e \text { min }}$ and $R_{S}$ is the mean volumetric radius of the Sun. Knowing the $S R$ to the solar pole, the observers elevation from the solar pole can be determined using the sine rule as, 


$$
\epsilon=i_{s e}-\sin ^{-1}\left[\frac{R_{S} \cos i_{s e}}{\sqrt{R_{S}^{2}+r^{2}-2 R_{S} r \sin i_{s e}}}\right]
$$

where $i_{s e}>i_{s e, \min }$. The Observer-to-Solar pole zenith angle, OZA, is thus simply,

$$
O Z A=\frac{\pi}{2}-\epsilon
$$

Note that Eq. (1) and (2) can be converted into the standard ecliptic plane reference plane by addition of 7.25 degrees to the given inclination, i.e. $i=i_{s e}+7.25^{\circ}$. Assuming a circular orbit, the spacecraft mean motion can be used to determine the time that the observer will be able to maintain an Observer-to-Solar pole zenith angle above a given defined minimum.

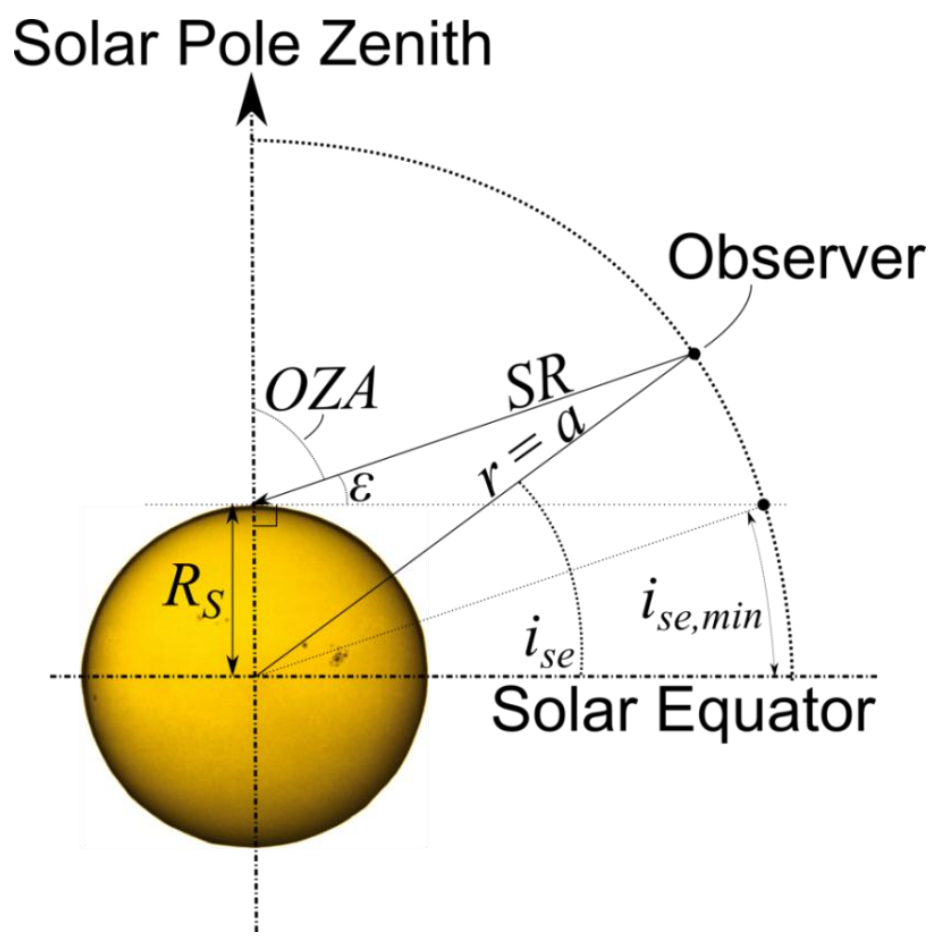

Fig. 2 Solar pole visibility; note that the solar equator is offset from the ecliptic plane by 7.25 degrees

The time below an Observer-to-Solar pole zenith angle of 30 degrees and 50 degrees over a range of semimajor axis and inclinations, with inclination measured from the ecliptic plane, is shown in Fig. 3. It is seen that the minimum required Observer-to-Solar pole zenith angle critically defines the time that the solar pole is visible and hence critically defines the minimum orbit radius at which a complete rotation of the Sun would be visible during a single orbit pass over the solar pole. Adopting the sidereal rotation period of the Sun as 609.12-hr (25.38 days), based on a solar latitude of 16 degrees, it is found that at a orbit radius of 0.4 au a solar polar orbit (orbit inclination 82.75 degrees) can maintain an Observer-to-Solar pole zenith angle below 50 degrees for a complete rotation of the Sun. Increasing the orbit radius of $0.5 \mathrm{au}$, it is found that the Observer-to-Solar pole 
zenith angle can be maintained below 40 degrees for the same duration at an orbit inclination of 78 degrees, but that the Observer-to-Solar pole zenith angle cannot be maintained below 30 degrees at any inclination for this duration. Finally, increasing the orbit radius to $0.6 \mathrm{au}$, the Observer-to-Solar pole zenith angle can be maintained below 40 degrees for this duration at an orbit inclination of 70 degrees, and can be maintained below 30 degrees for the required duration at an orbit inclination of 80 degrees.

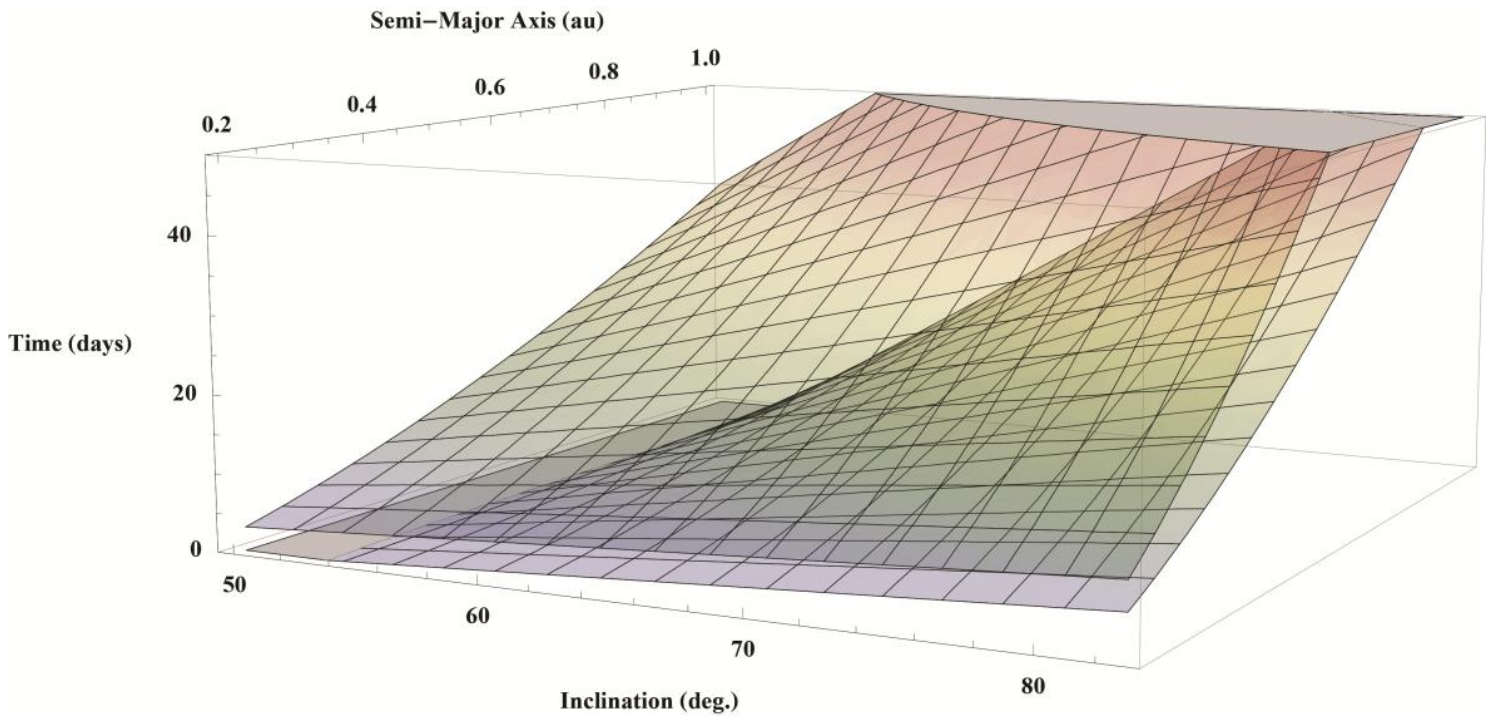

Fig. 3 Time below an Observer-to-Solar pole zenith angle of $30 \mathrm{deg}$. (bottom) and $50 \mathrm{deg}$. (top) over a range of semi-major axis and inclinations.

\section{B. Transfer Trajectory}

It has been seen previously that for solar sail transfers to high-inclination, circular orbits the trajectory can be divided into multiple phases [3-6,10-13]. Phase 1 is the reduction of orbit radius to below the target radius, whilst perhaps performing some modest plane change maneuver at the same time. Phase 2 is the rapid increase of orbit inclination while maintaining a near-constant orbit radius and Phase 3 is increasing the orbit radius to the target value, whilst perhaps performing some modest plane change maneuver at the same time. In [3 $-6,10-13]$ the optimal level of plane-change in each phase was simply defined using empirical evidence based on the use of either, local and/or global numerical optimization techniques, or semi-analytical approximations. However, in [15] orbit averaging techniques are used to develop a general perturbations solution of circle-tocircle low-thrust trajectory transfers with plane-change about the Sun that allow the optimal level of plane change in Phase 1 to be analytically derived. In [15] it is found that the minimum time, analytically derived, solar sail transfer is within $1 \%$ of the optimal transfer.

It has been shown previously that a three-phase transfer can be used to minimize either the transfer time or the technology requirements on the solar sail [6]. That is, for fixed transfer duration, the required sail size can be minimized by correctly defining the orbit radius in Phase 2 . As this radius is reduced the spacecraft size 
increases due to the thermal loading on the spacecraft, however the sail performance also increases due to the $\left(1 / r^{2}\right)$ variation in sail performance, reducing the required sail size. In [6] it is shown that a turning point can be defined at which the mass penalty due to the thermal loadings overcomes the increase in sail performance, this turning point defines the minimum sail technology requirement design point. However, the analysis in [6] does not directly consider spacecraft or mission cost, and it is likely that the trajectory profile for a minimum cost mission would increase the Phase 2 radius above both the time optimal and sail technology optimal radius. Indeed assuming the target orbit radius is less than that of, say, Venus', it is likely that the minimum cost mission would result in the removal of phase three, with phase two occurring at the target orbit radius and hence the spacecraft thermal design load would be the target/operational orbit radius and not that during the transfer trajectory.

The presented analysis assumes a two-phase trajectory using [15], whereby the orbit radius is restricted to greater than or equal to the target orbit radius in an attempt to minimize the technology requirements across the complete spacecraft system. Considering a solar sail propelled spacecraft transfer from a circular 1 au orbit within the ecliptic plane to a circular orbit of semi-major axis $a_{1}$ inclined at a target inclination of $i_{t}$, it is shown in [15] that the total transfer time (in seconds) can be written in the form,

$$
t=\frac{1}{\pi \beta}\left[\frac{1}{\cos \tilde{\gamma}}\left(\mathfrak{U}-\mathfrak{B} a_{1}^{\frac{3}{2}}\right)+a_{1}^{\frac{3}{2}}\left(\mathfrak{C} i_{t}+\tan \tilde{\gamma}\left(\mathfrak{B} \log \left[a_{1}\right]-\mathfrak{D}\right)\right)\right]
$$

where, $\mathfrak{A}, \mathfrak{B}, \mathfrak{C}$ and $\mathfrak{D}$ are all constants determined by the orbit parameters, the value of which is not relevant to this analysis, $\beta$ is the sail lightness number [16], and $\tilde{\gamma}$ switches between $\{-\gamma,+\gamma\}$ and is an augmented form of the sail clock angle, $\delta,[16]$, measured from the orbit transverse axis towards the normal axis. As such, $\gamma=$ $(\pi / 2-\delta)$, meaning that the augmented clock angle, $\tilde{\gamma}$, will switch sign at true anomaly $(\pi / 2)$ and $(3 \pi / 2)$ when considering the change of orbit inclination. Analysis of Eq. (4) shows that the trip time is minimized when the out-of-plane thrust angle is $0<\gamma<(\pi / 2)$ and that a turning point can be identified when the trip time is minimized.

Equation (4) cannot be generalized for the optimal case due to the variation in the optimal out of plane thrust angle, $\tilde{\gamma}$, with target orbit radius. However, in [15] the optimal out of plane thrust angle is approximated using a third order polynomial, allowing Eq. (4) to be re-written as, 


$$
\begin{aligned}
t=\frac{1}{\pi \beta}\left[\frac{\left(\mathfrak{A}+\mathfrak{B} a_{1}^{\frac{3}{2}}\right)}{\cos \left[\mathfrak{C}\left(\mathfrak{D}+a_{1}\right)\left(\mathfrak{E}+\mathfrak{F} a_{1}+a_{1}^{2}\right)\right]}\right. \\
\\
\left.\quad+a_{1}^{\frac{3}{2}}\left(\mathfrak{G} i_{t}+\left(\mathfrak{H}+\mathfrak{J} \log \left[a_{1}^{\frac{3}{2}}\right]\right) \tan \left[\mathfrak{J}+\mathfrak{K} a_{1}+\mathfrak{L} a_{1}^{2}+\mathfrak{M} a_{1}^{3}\right]\right)\right] \text { years }
\end{aligned}
$$

where $\mathfrak{A}, \mathfrak{B}, \mathfrak{C}, \mathfrak{D}, \mathfrak{E}, \mathfrak{F}, \mathfrak{H}, \mathfrak{H}, \mathfrak{J}, \mathfrak{J}, \mathfrak{K}, \mathfrak{L}$ and $\mathfrak{M}$ are constants determined by the orbit parameters, distinct from those used in Eq. (4), and are defined in Table 1, and where $a_{1}$ is measured in meters and $t$ in seconds.

Table 1 Constants for Eq. (5)

\begin{tabular}{cl}
\hline \hline Constant & \multicolumn{1}{c}{ Value } \\
\hline $\mathfrak{U}$ & 0.43303013661188056 \\
$\mathfrak{B}$ & $-7.483934949353608 \times 10^{-18}$ \\
$\mathfrak{C}$ & $3.4425263133185114 \times 10^{-34}$ \\
$\mathfrak{D}$ & $-8.392144253966071 \times 10^{+9}$ \\
$\mathfrak{E}$ & $3.5784751639989546 \times 10^{+22}$ \\
$\mathfrak{J}$ & $-1.995309183700735 \times 10^{+11}$ \\
$\mathfrak{G}$ & $3.5267212585249795 \times 10^{-17}$ \\
$\mathfrak{H}$ & $2.8885612757886467 \times 10^{-16}$ \\
$\mathfrak{I}$ & $-7.483934949353608 \times 10^{-18}$ \\
$\mathfrak{I}$ & 0.103382782379 \\
$\mathfrak{K}$ & $-1.2895443276860758 \times 10^{-11}$ \\
$\mathfrak{L}$ & $7.157806142290288 \times 10^{-23}$ \\
$\mathfrak{M}$ & $-3.4425263133185114 \times 10^{-34}$ \\
\hline \hline
\end{tabular}

Using Eq. (5) the attainable orbit region within five years is shown in Fig. 4 for a range of sail characteristic accelerations [16], a metric of solar sail performance; Fig. 4 also shows the orbit region that is required to be obtained to enable 25-day observation of the poles at a range of maximum observer-to-solar pole zenith angles. It is seen in Fig. 4 that with a sail characteristic acceleration of $0.2 \mathrm{~mm} / \mathrm{s}^{2}$ a peak solar latitude of 60 degrees cannot be reached in 5-years. However, with a sail characteristic acceleration of 0.3 and $0.4 \mathrm{~mm} / \mathrm{s}^{2}$ a peak solar latitude of 60 degrees at orbit radius 0.43 and 0.62 au, respectively, can be reached in a similar timeframe. It is also seen in Fig. 4 that restricting sail characteristic acceleration to below $0.5 \mathrm{~mm} / \mathrm{s}^{2}$, it is not possible using a two-phase 5-year transfer trajectory to attain a solar orbit that maintains the observer-to-solar pole zenith angle below 30 degrees for 25 days. It is seen however that a sail characteristic acceleration below $0.5 \mathrm{~mm} / \mathrm{s}^{2}$ can, using a two phase 5-year transfer trajectory, attain a solar orbit that maintains the observer-to-solar pole zenith angle below 40 degrees for 25 days.

From Fig. 4 it is apparent that a range of two-phase transfer trajectories are possible within any set of mission requirements. Assuming the spacecraft is required to reach an orbit inclination of 52.75 degrees in 5- 
years, equivalent to a peak solar latitude of 60 degrees, and that the final observer-to-solar pole zenith angle should be less than 40 degrees, and ideally should be less than 30 degrees, during a sidereal rotation period of the Sun, the range of two-phase transfer trajectories are defined by the observer-to-solar pole zenith angle 30 and 40 degree contour lines, giving a target solar radii between 0.550 au and $0.447 \mathrm{au}$. Table 2 summaries a range of possible mission architectures, with an increasing level of technology requirement on the solar sail, ranging from a characteristic acceleration of $0.28 \mathrm{~mm} \mathrm{~s}^{-2}$ up to $0.53 \mathrm{~mm} \mathrm{~s}^{-2}$.

\section{System Analysis}

\section{A. Generic Gossamer Structure Model}

A generic gossamer structure / solar sail model is used to allow general top-level technology capabilities to be analyzed and quantified. It should be noted that this generic gossamer structure / solar sail model is not intended to be a complete or final model, but rather is intended to allow general top-level technology capabilities to be analyzed and quantified.

Noting that the possible films typically considered range in density from Polyethylene terephthalate (PET) at $1350 \mathrm{~kg} \mathrm{~m}^{-3}$ to LaRCT-CP1 at $1430 \mathrm{~kg} \mathrm{~m}^{-3}$, the generic model is similarly based on Kapton film as this is one of the heaviest films likely to be used. In addition to the film, an allocation of $0.42 \mathrm{~g} \mathrm{~m}^{-2}$ is given for adhesives and edge enhancement, but without swivels and without constant force springs. Sail film thickness can be arbitrarily selected, however $7.5 \mu \mathrm{m}$ and $2.5 \mu \mathrm{m}$ films will be considered.

Assuming a 3-axis stabilized gossamer structure, as opposed to a spin-stabilized structure, the support booms for the structure are a primary technology requirement. The impact of boom technology can hence also be quantified within the generic gossamer structure / solar sail model as shown in Fig. 5, which presents the range of possible sail assembly loadings over sail length sizes from $35-125$ m. Note within Fig. 5 the DLR boom technology is described within [17, 18], whilst the CoilAble booms are described in [19]. It should also be noted that the inflatable booms developed by L'Garde [20 - 22] for use in the NASA-funded Sunjammer mission have a lower specific mass than the booms considered in Fig. 5; however, this data is not in the public domain. The boom technology specific mass data points impose a quasi-limit on the gossamer structure / solar sail model to side lengths of less than or equal to $125 \mathrm{~m}$. 


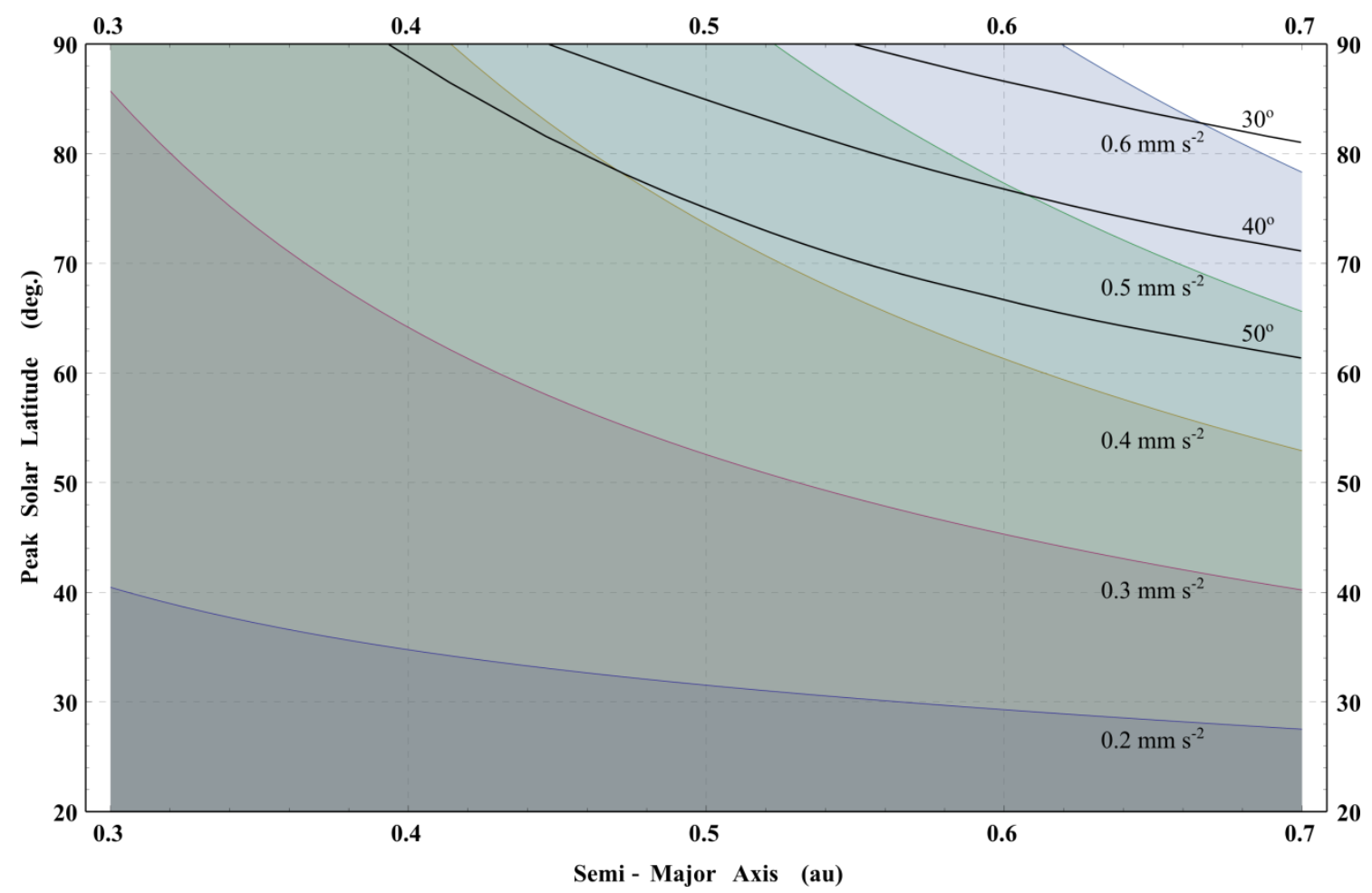

Fig. 4 Attainable peak solar latitude and semi-major axis within 5-years for a sail characteristic accelerations of $0.2 \mathrm{~mm} \mathrm{~s}^{-2}$ (bottom); $0.3 \mathrm{~mm} \mathrm{~s}^{-2} ; 0.4 \mathrm{~mm} \mathrm{~s}^{-2} ; 0.5 \mathrm{~mm} \mathrm{~s}^{-2} ; 0.6 \mathrm{~mm} \mathrm{~s}^{-2}$ (top); 25-day maximum observer-to-solar pole zenith angle contours also shown.

Table 2 Summary and comparison of solar sail mission architecture options and requirements; superscript number indicates number of trajectory phases

\begin{tabular}{|c|c|c|c|c|c|c|}
\hline & $\overline{A^{2}}$ & $\mathrm{~A}+{ }^{2}$ & $\mathbf{B}^{2}$ & $\mathrm{~B}+{ }^{2}$ & $\mathbf{C}^{2}$ & $\mathrm{C}+{ }^{2}$ \\
\hline $\begin{array}{l}\text { Solar pole maximum } \\
\text { OZA in one-sidereal } \\
\text { rotation period }\end{array}$ & $50 \mathrm{deg}$. & $50 \mathrm{deg}$. & $40 \mathrm{deg}$. & $40 \mathrm{deg}$. & $30 \mathrm{deg}$. & $30 \mathrm{deg}$. \\
\hline Target orbit radius & $0.397 \mathrm{au}$ & $0.397 \mathrm{au}$ & $0.461 \mathrm{au}$ & $0.461 \mathrm{au}$ & $0.559 \mathrm{au}$ & $0.559 \mathrm{au}$ \\
\hline $\begin{array}{l}\text { Required sail } \\
\text { characteristic } \\
\text { acceleration }\end{array}$ & $0.29 \mathrm{~mm} / \mathrm{s}^{2}$ & $0.39 \mathrm{~mm} / \mathrm{s}^{2}$ & $0.32 \mathrm{~mm} / \mathrm{s}^{2}$ & $0.44 \mathrm{~mm} / \mathrm{s}^{2}$ & $0.37 \mathrm{~mm} / \mathrm{s}^{2}$ & $0.54 \mathrm{~mm} / \mathrm{s}^{2}$ \\
\hline Phase 1 duration & 2.4 years & 1.8 years & 2.1 years & 1.5 years & 1.7 years & 1.1 years \\
\hline $\begin{array}{l}\text { Inclination at end of } \\
\text { phase } 1\end{array}$ & $8.8^{\circ}$ & $8.8^{\circ}$ & $8.8^{\circ}$ & $8.8^{\circ}$ & $8.5^{\circ}$ & $8.5^{\circ}$ \\
\hline Time to $60^{\circ}$ latitude & 5.0 years & 3.7 years & 5.0 years & 3.6 years & 5.0 years & 3.4 years \\
\hline Time to $90^{\circ}$ latitude & 6.8 years & 5.0 years & 7.0 years & 5.0 years & 7.3 years & 5.0 years \\
\hline $\begin{array}{l}\text { Time to } 50^{\circ} \mathrm{OZA} \\
\text { view pole over a } \\
\text { sidereal rotation }\end{array}$ & 6.8 years & 5.0 years & 6.3 years & 4.5 years & 5.8 years & 4.0 years \\
\hline $\begin{array}{l}\text { Time to } 40^{\circ} \mathrm{OZA} \\
\text { view pole over a } \\
\text { sidereal rotation }\end{array}$ & $\mathrm{n} / \mathrm{a}$ & $\mathrm{n} / \mathrm{a}$ & 7.0 years & 5.0 years & 6.5 years & 4.5 years \\
\hline $\begin{array}{l}\text { Time to } 30^{\circ} \mathrm{OZA} \\
\text { view pole over a } \\
\text { sidereal rotation }\end{array}$ & $\mathrm{n} / \mathrm{a}$ & $\mathrm{n} / \mathrm{a}$ & $\mathrm{n} / \mathrm{a}$ & $\mathrm{n} / \mathrm{a}$ & 7.3 years & 5.0 years \\
\hline
\end{tabular}




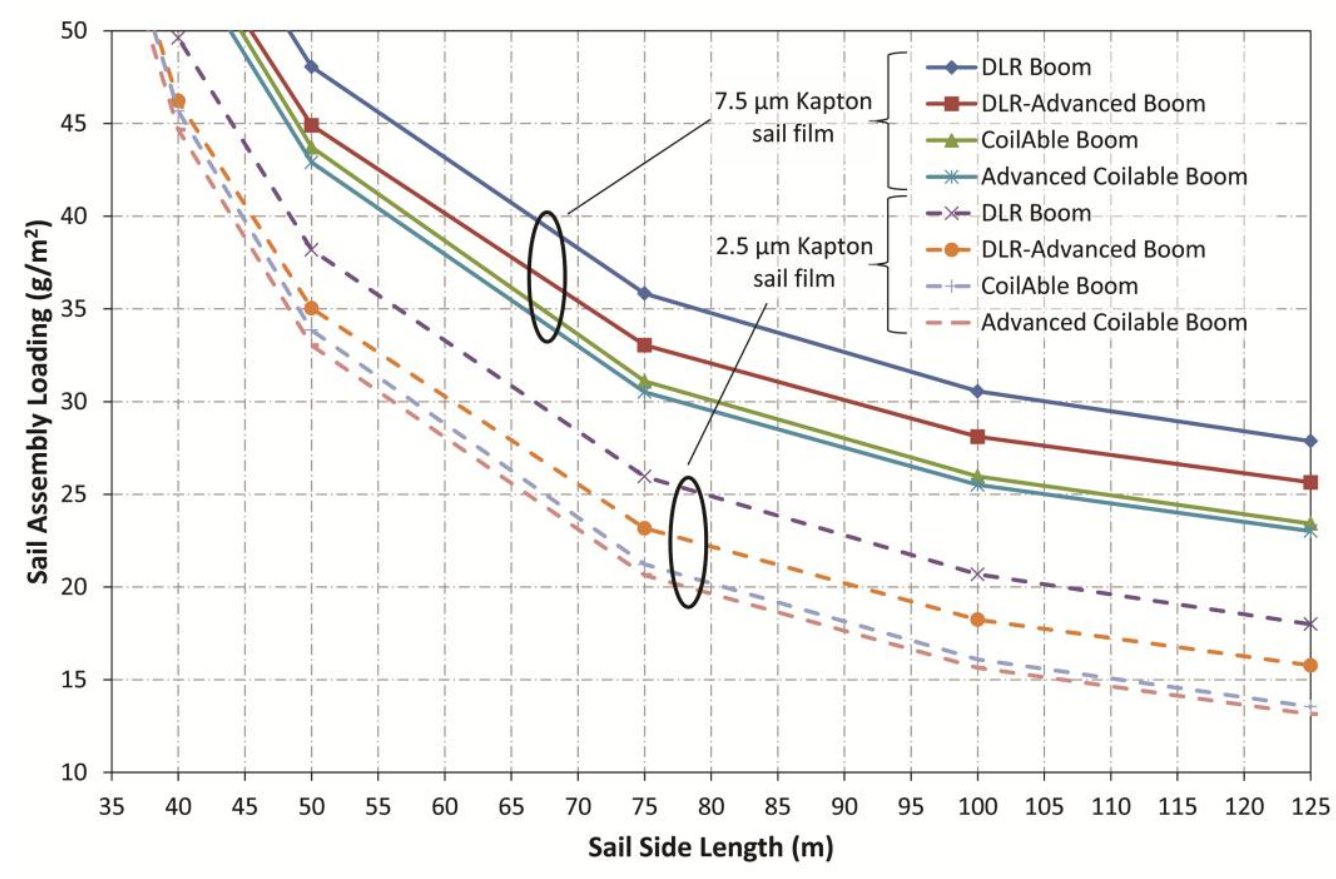

Fig. 5 Sail assembly loading using generic gossamer structure / solar sail model over a range of sail lengths and technology levels.

\section{B. System Mass Budget Allowances}

For each mission architecture option detailed in Table 2 the generic gossamer structure / solar sail model illustrated in Fig. 5 can be used to determine a platform mass allowance for of the required performance level of that mission architecture as shown in Table 3 - Table 8. Note that the platform mass allowance is given for the two film thicknesses considered and as a range over the boom technologies considered as in Fig. 5.

Table 3 Summary of mission architecture option $\mathrm{A}^{2}$ mass allowance estimates, including ROM payload allowance estimate.

\begin{tabular}{lllll}
\hline \hline & \multicolumn{4}{c}{ Architecture option $\mathbf{A}^{\mathbf{2}}$} \\
\hline $\begin{array}{c}\text { GO Side } \\
\text { Length (m) }\end{array}$ & $\begin{array}{c}\text { GO Mass Range } \\
\text { with 7.5 } \boldsymbol{\mu m} \text { film } \\
(\mathbf{k g})\end{array}$ & $\begin{array}{c}\text { GO Mass Range } \\
\text { with } \mathbf{2 . 5} \boldsymbol{\mu} \mathbf{m} \text { film } \\
(\mathbf{k g})\end{array}$ & $\begin{array}{c}\text { Platform Mass } \\
\text { range with 7.5 } \boldsymbol{\mu m} \\
\text { film }(\mathbf{k g})\end{array}$ & $\begin{array}{c}\text { Platform Mass } \\
\text { range with } \mathbf{2 . 5} \boldsymbol{\mu m} \\
\text { film }(\mathbf{k g})\end{array}$ \\
\hline 50 & $120-107$ & $95-83$ & negative & negative \\
75 & $202-172$ & $146-116$ & $<12$ & $38-67$ \\
100 & $306-255$ & $207-156$ & $21-71$ & $120-170$ \\
125 & $435-360$ & $281-205$ & $75-150$ & $229-305$ \\
\hline \hline
\end{tabular}

Table 4 Summary of mission architecture option $\mathrm{A}+{ }^{2}$ mass allowance estimates, including ROM payload allowance estimate.

\begin{tabular}{lllll}
\hline \hline & \multicolumn{4}{c}{ Architecture option $\mathbf{A +}$} \\
\hline $\begin{array}{c}\text { GO Side } \\
\text { Length (m) }\end{array}$ & $\begin{array}{c}\text { GO Mass Range } \\
\text { with 7.5 } \boldsymbol{\mu m} \text { film } \\
(\mathbf{k g})\end{array}$ & $\begin{array}{c}\text { GO Mass Range } \\
\text { with } \mathbf{2 . 5} \boldsymbol{\mu m} \text { film } \\
(\mathbf{k g})\end{array}$ & $\begin{array}{c}\text { Platform Mass } \\
\text { range with } \mathbf{7 . 5} \boldsymbol{\mu m} \\
\text { film }(\mathbf{k g})\end{array}$ & $\begin{array}{c}\text { Platform Mass } \\
\text { range with } \mathbf{2 . 5} \boldsymbol{\mu m} \\
\text { film }(\mathbf{k g})\end{array}$ \\
\hline 50 & $120-107$ & $95-83$ & negative & negative \\
75 & $202-172$ & $146-116$ & negative & $<20$ \\
100 & $306-255$ & $207-156$ & negative & $34-85$ \\
125 & $435-360$ & $281-205$ & $<17$ & $96-172$ \\
\hline \hline
\end{tabular}


Table 5 Summary of mission architecture option $\mathrm{B}^{2}$ mass allowance estimates, including ROM payload allowance estimate.

\begin{tabular}{lllll}
\hline \hline & \multicolumn{4}{c}{ Architecture option $\mathbf{B}^{2}$} \\
\hline $\begin{array}{c}\text { GO Side } \\
\text { Length (m) }\end{array}$ & $\begin{array}{c}\text { GO Mass Range } \\
\text { with 7.5 } \boldsymbol{\mu m} \text { film } \\
(\mathbf{k g})\end{array}$ & $\begin{array}{c}\text { GO Mass Range } \\
\text { with } \mathbf{2 . 5} \boldsymbol{\mu m} \text { film } \\
(\mathbf{k g})\end{array}$ & $\begin{array}{c}\text { Platform Mass } \\
\text { range with 7.5 } \boldsymbol{\mu m} \\
\text { film }(\mathbf{k g})\end{array}$ & $\begin{array}{c}\text { Platform Mass } \\
\text { range with } \mathbf{2 . 5} \boldsymbol{\mu m} \\
\text { film }(\mathbf{k g})\end{array}$ \\
\hline 50 & $120-107$ & $95-83$ & negative & negative \\
75 & $202-172$ & $146-116$ & negative & $20-49$ \\
100 & $306-255$ & $207-156$ & $<39$ & $87-138$ \\
125 & $435-360$ & $281-205$ & $24-100$ & $179-254$ \\
\hline \hline
\end{tabular}

Table 6 Summary of mission architecture option $\mathrm{B}+{ }^{2}$ mass allowance estimates, including $\mathrm{ROM}$ payload allowance estimate.

\begin{tabular}{lllll}
\hline \hline & \multicolumn{4}{c}{ Architecture option B+ } \\
\hline $\begin{array}{c}\text { GO Side } \\
\text { Length (m) }\end{array}$ & $\begin{array}{c}\text { GO Mass Range } \\
\text { with 7.5 } \boldsymbol{\mu m} \text { film } \\
(\mathbf{k g})\end{array}$ & $\begin{array}{c}\text { GO Mass Range } \\
\text { with } \mathbf{2 . 5} \boldsymbol{\mu m} \text { film } \\
(\mathbf{k g})\end{array}$ & $\begin{array}{c}\text { Platform Mass } \\
\text { range with } \mathbf{7 . 5} \boldsymbol{\mu m} \\
\text { film } \mathbf{( k g )}\end{array}$ & $\begin{array}{c}\text { Platform Mass } \\
\text { range with } \mathbf{2 . 5} \boldsymbol{\mu m} \\
\text { film }(\mathbf{k g})\end{array}$ \\
\hline 50 & $120-107$ & $95-83$ & negative & negative \\
75 & $202-172$ & $146-116$ & negative & $<2$ \\
100 & $306-255$ & $207-156$ & negative & $4-54$ \\
125 & $435-360$ & $281-205$ & negative & $48-124$ \\
\hline \hline
\end{tabular}

Table 7 Summary of mission architecture option $C^{2}$ mass allowance estimates, including ROM payload allowance estimate.

\begin{tabular}{lllll}
\hline \hline & \multicolumn{4}{c}{ Architecture option $\mathbf{C}^{\mathbf{2}}$} \\
\hline $\begin{array}{c}\text { GO Side } \\
\text { Length }(\mathbf{m})\end{array}$ & $\begin{array}{c}\text { GO Mass Range } \\
\text { with 7.5 } \boldsymbol{\mu m} \text { film } \\
(\mathbf{k g})\end{array}$ & $\begin{array}{c}\text { GO Mass Range } \\
\text { with } \mathbf{2 . 5} \boldsymbol{\mu m} \text { film } \\
(\mathbf{k g})\end{array}$ & $\begin{array}{c}\text { Platform Mass } \\
\text { range with } \mathbf{7 . 5} \boldsymbol{\mu m} \\
\text { film } \mathbf{( k g )}\end{array}$ & $\begin{array}{c}\text { Platform Mass } \\
\text { range with } \mathbf{2 . 5} \boldsymbol{\mu m} \\
\text { film }(\mathbf{k g})\end{array}$ \\
\hline 50 & $120-107$ & $95-83$ & negative & negative \\
75 & $202-172$ & $146-116$ & negative & $<26$ \\
100 & $306-255$ & $207-156$ & negative & $45-96$ \\
125 & $435-360$ & $281-205$ & $<34$ & $113-188$ \\
\hline \hline
\end{tabular}

Table 8 Summary of mission architecture option $\mathrm{C}+{ }^{2}$ mass allowance estimates, including $\mathrm{ROM}$ payload allowance estimate.

\begin{tabular}{lllll}
\hline \hline & \multicolumn{4}{c}{ Architecture option $\mathbf{C +}$} \\
\hline $\begin{array}{c}\text { GO Side } \\
\text { Length (m) }\end{array}$ & $\begin{array}{c}\text { GO Mass Range } \\
\text { with } \mathbf{7 . 5} \boldsymbol{\mu m} \text { film } \\
(\mathbf{k g})\end{array}$ & $\begin{array}{c}\text { GO Mass Range } \\
\text { with } \mathbf{2 . 5} \boldsymbol{\mu m} \text { film } \\
(\mathbf{k g})\end{array}$ & $\begin{array}{c}\text { Platform Mass } \\
\text { range with } \mathbf{7 . 5} \boldsymbol{\mu m} \\
\text { film }(\mathbf{k g})\end{array}$ & $\begin{array}{c}\text { Platform Mass } \\
\text { range with } \mathbf{2 . 5} \boldsymbol{\mu m} \\
\text { film }(\mathbf{k g})\end{array}$ \\
\hline 50 & $120-107$ & $95-83$ & negative & negative \\
75 & $202-172$ & $146-116$ & negative & negative \\
100 & $306-255$ & $207-156$ & negative & $<17$ \\
125 & $435-360$ & $281-205$ & negative & $<65$ \\
\hline \hline
\end{tabular}

\section{Payload Budget}

Three science priorities have been identified [9]. The first two require long-duration observations at highlatitudes. The first is latitudinal variations of solar irradiance and requires a payload mass allocation of $5 \mathrm{~kg}$ to carry a Total Solar Irradiance instrument. The second priority considers the internal solar structure and dynamo, and increases the payload mass allocation requirement to $15 \mathrm{~kg}$ with the addition of Doppler velocity and magnetic field instruments. The third scenario addresses Heliophysics and dynamo issues and requires a payload 
of remote and in-situ instruments including Doppler and Stokes Imager, Heliospheric imager (coronagraph), Magnetometer, Solar Wind Analyzer (Suprathermal elec.) and Energetic Particle Detector. The third scenario requires a payload mass of $40 \mathrm{~kg}$.

\section{System Mass Budget Analysis}

A parametric, bottom-up, system mass budget analysis was developed to allow the platform mass, without the solar sail, to be evaluated across a range of payload masses and minimum orbit radius. The analysis is restricted to technology assessed as TRL 6 or greater, and is based on worst-case assumptions to ensure a suitably conservative mass budget estimate. The results from the parametric, bottom-up, system mass budget analysis are shown in Fig. 6; note that this analysis, as before, is intended to inform analysis of the 'sufficient value' minimum science payload and hence is intended only as an indicative mass estimate.

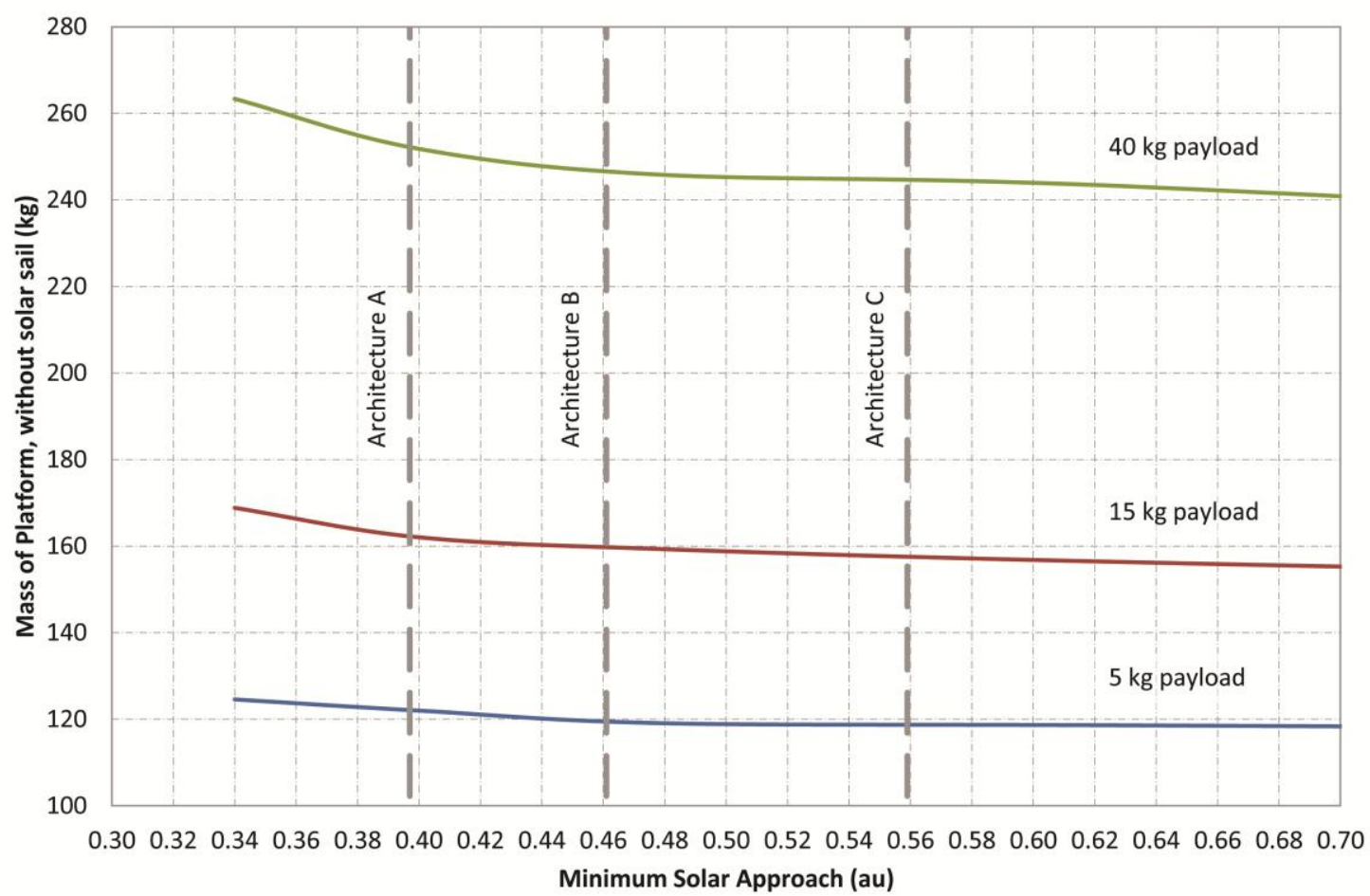

Fig. 6 Platform mass budget analysis across a range of minimum solar approaches and payload masses

From Fig. 6 and Table 3 - Table 8 the required sail size and technology for each mission architecture and payload mass can be established.

\section{Architecture A}

It is found that Architecture $\mathrm{A}+{ }^{2}$ is restricted to a payload mass of less than about $15 \mathrm{~kg}$, assuming both $2.5 \mu \mathrm{m}$ film and a boom specific mass of order $70 \mathrm{~g} / \mathrm{m}$ on a sail of side length $125 \mathrm{~m}$. Meanwhile, Architecture $\mathrm{A}^{2}$ can deliver a $40 \mathrm{~kg}$ payload with a $2.5 \mu \mathrm{m}$ film and a boom specific mass of order $145 \mathrm{~g} / \mathrm{m}$ on a sail of side length 
$125 \mathrm{~m}$. Alternatively, a reduced payload of $15 \mathrm{~kg}$ is enabled with a reduced boom specific mass to order $70 \mathrm{~g} / \mathrm{m}$ on a sail of side length $100 \mathrm{~m}$ or a payload of $5 \mathrm{~kg}$ with an increased boom specific mass to order $190 \mathrm{~g} / \mathrm{m}$. A 5 $\mathrm{kg}$ payload can also be delivered with a $7.5 \mu \mathrm{m}$ film and a boom specific mass of order $100 \mathrm{~g} / \mathrm{m}$ on a sail of side length $125 \mathrm{~m}$.

\section{Architecture B}

It is found that Architecture $\mathrm{B}+{ }^{2}$ is restricted to a payload mass of less than about $5 \mathrm{~kg}$, assuming both $2.5 \mu \mathrm{m}$ film and a boom specific mass of order $70 \mathrm{~g} / \mathrm{m}$ on a sail of side length $125 \mathrm{~m}$. Meanwhile, Architecture $\mathrm{B}^{2}$ is can deliver a $40 \mathrm{~kg}$ payload with a $2.5 \mu \mathrm{m}$ film and a boom specific mass of order $70 \mathrm{~g} / \mathrm{m}$ on a sail of side length $125 \mathrm{~m}$. Alternatively, a reduced payload of $15 \mathrm{~kg}$ is possible with an increased boom specific mass to order 240 $\mathrm{g} / \mathrm{m}$ on a similar size side or a payload of $5 \mathrm{~kg}$ with a boom specific mass to order $90 \mathrm{~g} / \mathrm{m}$ on a sail of side length $100 \mathrm{~m}$.

\section{Architecture $C$}

It is found that Architecture $\mathrm{C}+{ }^{2}$ is not feasible with a meaningful payload mass, while Architecture $\mathrm{C}^{2}$ is restricted to a sail of side length $125 \mathrm{~m}$, with $2.5 \mu \mathrm{m}$ film with a boom specific mass to order $120 \mathrm{~g} / \mathrm{m}(15 \mathrm{~kg}$ payload) too $200 \mathrm{~g} / \mathrm{m}(5 \mathrm{~kg}$ payload $)$.

\section{Analysis}

It is of note that in all architectures, except one, the $7.5 \mu \mathrm{m}$ film does not provide a sufficiently meaningful payload mass allocation, and in the one architecture where it does the payload mass is limited to around $5 \mathrm{~kg}$ on a $125 \mathrm{~m}$ sail side length. Meanwhile the feasible payload mass appears much less sensitive to the considered variation in boom specific mass.

\section{Conclusions}

Analysis of a Solar Polar Mission design trade-space to inform required future technology development, whilst seeking to inform analysis of the 'sufficient value' minimum science payload, showed that a $40 \mathrm{~kg}$ instrument payload can only feasibly be delivered to a maximum solar pole observer-to-zenith angle in one solar sidereal rotation period of 40 degrees or more. Further, a sail of side length $125 \mathrm{~m}$ would be required to achieve this, along with $2.5 \mu \mathrm{m}$ film substrate and a boom specific mass of order $70-145 \mathrm{~g} / \mathrm{m}$, corresponding to a $40-$ 50 degree maximum solar pole observer-to-zenith angle in one solar sidereal rotation period after $7-6.8$ years, respectively. It was found that a $15 \mathrm{~kg}$ instrument payload could feasibly be delivered to a maximum solar pole observer-to-zenith angle in one solar sidereal rotation period of 30 degrees or more, and that a $2.5 \mu \mathrm{m}$ film was again required. This lower observation angle can be achieved in 7.3 years by maintaining a sail side-length of $125 \mathrm{~m}$ and a boom specific mass of order $120 \mathrm{~g} / \mathrm{m}$. Alternatively, the boom technology requirements, or the transfer time, can be reduced for an increased observation angle. For example, maintaining a sail side-length of 
$125 \mathrm{~m}$ the boom specific mass can be increased to around $240 \mathrm{~g} / \mathrm{m}$, corresponding to a 40-degree maximum solar pole observer-to-zenith angle in one solar sidereal rotation period after 7-years. On the other hand, the sail size can be reduced to a side-length of $100 \mathrm{~m}$, with a boom specific mass to order $70 \mathrm{~g} / \mathrm{m}$, corresponding to a 50 degree maximum solar pole observer-to-zenith angle in one solar sidereal rotation period after 6.8-years. As expected, a $5 \mathrm{~kg}$ payload offers the most flexibility on solar pole observer-to-zenith angle, sail technology and transfer time. It was found that only a $5 \mathrm{~kg}$ payload could be considered with a $7.5 \mu \mathrm{m}$ film substrate, corresponding to a 50-degree maximum solar pole observer-to-zenith angle in one solar sidereal rotation period after 6.8 years with a boom specific mass of order $100 \mathrm{~g} / \mathrm{m}$.

\section{References}

[1] Marsch, E., Marsden, R., Harrison, R., Wimmer-Schweingruber, R., Fleck, B., "Solar Orbiter-mission profile, main goals and present status", Advances in Space Research, Vol. 36, No. 8, 2005, pp. 1360 - 1366.

[2] Macdonald, M., M'Innes, C.R., "Solar sail science mission applications and advancement: solar sailing: concepts, technology, missions", Advances in Space Research, Vol. 48, No. 11, 2011, pp. 1702-1716.

[3] Wright, J.L. and Warmke, J.M., "Solar Sail Mission Applications", Paper 76-808, AIAA/AAS Astrodynamics Conference, San Diego, California, August 18-20, 1976.

[4] Sauer, C. G., Jr., "Solar Sail Trajectories for Solar-Polar and Interstellar Probe Missions," AAS 99-336, Proceedings of AAS/AIAA Astrodynamics Specialists Conference, Girdwood, Alaska, August 1999.

[5] Goldstein, B., Buffington, A., Cummings, A.C., Fisher, R., Jackson, B.V., Liewer, P.C., Mewaldt, R.A., Neugebauer, M., "A Solar Polar Sail Mission: Report of a Study to Put a Scientific Spacecraft in a Circular Polar Orbit about the Sun", Proceedings of MTG: SPIE International Symposium on Optical Science, Engineering and Instrumentation, San Diego, California, July 1998.

[6] Macdonald, M., Hughes, G.W., MInnes, C.R., Lyngvi, A., Falkner, P., Atzei, A. "Solar polar orbiter: a solar sail technology reference study”, Journal of Spacecraft and Rockets, Vol. 43 No. 5, pp. 960-972, 2006.

[7] Geppert, U., Biering, B., Lura, F., Block, J., Straubel, M., Reinhard, R., "The 3-Step DLR-ESA Gossamer Road to Solar Sailing," Advances in Space Research, Vol. 48, No. 11, 2011, pp. 1695 - 1701.

[8] Spietz, P., Baturkin, V., Grundmann, T., Henning, F., Hobbie, C., Hölzel, M., Jetzschmann, M., Lura, F., Melnik, N., Pissarskoi, A., Quantius, D., Reershemius, S., Seefeldt, P., Spröwitz, T., Toth, N., Biering, B., "Gossamer Roadmap and Development of Gossamer-1, DLR's Membrane Deployment Demonstrator spacecraft", $3^{\text {rd }}$ International Symposium on Solar Sailing, Glasgow, Scotland, June 2013.

[9] Appourchaux, T., Gizon, L., Hirohisa, H., Takashi, S., Macdonald, M., "SOLARIS: Solar Sail Investigation

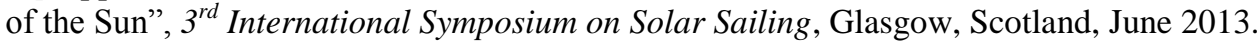

[10] Mooij, E., Noomen, R., Candy, S., "Evolutionary Optimization for a Solar Sailing Solar Polar Mission" AIAA 2006-6180, AIAA/AAS Astrodynamics Specialist Conference and Exhibit, Keystone, Colorado, August $21-24,2006$.

[11] Dachwald, B., Ohndorf, A., Wie, B., "Solar Sail Trajectory Optimization for the Solar Polar Imager (SPI) Mission”, AIAA 2006-6177, AIAA/AAS Astrodynamics Specialist Conference and Exhibit, Keystone, Colorado, August $21-24,2006$.

[12] Mengali, G., Quarta, A.A., "Solar Sail Near-Optimal Circular Transfers with Plane Change", Journal of Guidance, Control and Dynamics, Vol. 32, No. 2, pp. 456 - 463, 2009.

[13] Quarta, A.A., Mengali, G., "Approximate Solutions to Circle-to-Circle Solar Sail Orbit Transfers", Journal of Guidance, Control and Dynamics, In Press, 2013.

[14] Appourchaux, T., Liewer, P., Watt, M., Alexander, D., Andretta, V., Auchere, F., D'Arrigo, P., Ayon, J., Corbard, T., Fineschi, S., Finsterle, W., Floyd, L., Garbe, G., Gizon, L., Hassler, D., Harra, L., Kosovichev, A., Leibacher, J., Leipold, M., Murphy, N., Maksimovic, M., Martinez-Pillet, V., Matthews, BSA., Mewaldt, R., Moses, D., Newmark, J., Regnier, S., Schmutz, W., Socker, D., Spadaro, D., Stuttard, M., Trosseille, C., Ulrich, R., Velli, M., Vourlidas, A., Wimmer-Schweingruber, C.R., Zurbuchen, T., "POLAR Investigation of the Sun POLARIS", Experimental Astronomy, Vol. 23, pp. 1079 - 1117, 2009.

[15] Macdonald, M., "Analytical, Circle-to-Circle Low-Thrust Transfer Trajectories with Plane Change", AIAA Guidance, Navigation, and Control Conference, Boston, August 2013. 
[16] M'Innes, C.R., “Solar Sailing: Technology, Dynamics and Mission Applications”, Springer-Praxis, Chichester, 1999.

[17] Sickinger, C., Herbeck, L., "Deployment Strategies, Analysis and Tests for the CFRP Booms of a Solar Sail", In proceedings of European Conference on Spacecraft Structures, Materials and Mechanical Testing Conference, CNES, Toulouse, France, 2002.

[18] Herbeck, L., Sickinger, C., Eiden, M., Leipold, M., "Solar Sail hardware Developments", In proceedings of European Conference on Spacecraft Structures, Materials and Mechanical Testing Conference, CNES, Toulouse, France, 2002.

[19] Murphy, D.M., MEachen, M.E., Macy, B.D., gasper, J.L. "Demonstration of a 20-m Solar Sail System", AIAA 2005-2126, 46 ${ }^{\text {th }}$ AIAA/ASME/ASCE/AHS/ASC Structures, Structural Dynamics \& Materials Conference, Austin, Texas, 2005.

[20] Lichodziejewshi, D., Derbès, B., "Vacuum Deployment and Testing of a 4-Quadrant Scaleable Inflatable Rigidizable Solar Sail System", AIAA 2005-2122, 46 ${ }^{\text {th }}$ AIAA/ASME/ASCE/AHS/ASC Structures, Structural Dynamics \& Materials Conference, Austin, Texas, 2005.

[21] Sleight D.W., Michii, Y., Lichodziejewshi, D., Derbès, B., Mann, T.O., "Structural Analysis of an Inflation Deployment Solar Sail with Experimental Validation", AIAA 2005-3727, 41 ${ }^{\text {st }}$ AIAA/ASME/SAE/ASEE Joint Propulsion Conference \& Exhibit, Tucson, Arizona, 2005.

[22] Mann, T., Behun, V., Lichodziejewshi, D., Derbès, B., Sleight, D., "Ground Testing a 20-meter Inflation Deployed Solar Sail", AIAA 2006-1707, 47 $7^{\text {th }}$ AIAA/ASME/ASCE/AHS/ASC Structures, Structural Dynamics \& Materials Conference, Newport, Rhode Island, 2006. 